\title{
Disentangling the European Airlines Efficiency Puzzle: A Network Data Envelopment Analysis Approach*
}

\author{
Meryem Duygun \\ University of Hull
}

\author{
Diego Prior \\ Universitat Autònoma de Barcelona \\ Emili Tortosa-Ausina \\ Universitat Jaume I and Ivie
}

\author{
Mohamed Shaban \\ University of Leicester
}

June 15, 2015

\begin{abstract}
In recent years the European airline industry has undergone critical restructuring. It has evolved from a highly regulated market predominantly operated by national airlines to a dynamic, liberalized industry where airline firms compete freely on prices, routes, and frequencies. Although several studies have analyzed performance issues for European airlines using a variety of efficiency measurement methods, virtually none of them has considered two-stage alternatives - not only in this particular European context but in the airline industry in general. We extend the aims of previous contributions by considering a network Data Envelopment Analysis (network DEA) approach which comprises two sub-technologies that can share part of the inputs. Results show that, in general, most of the inefficiencies are generated in the first stage of the analysis. However, when considering different types of carriers several differences emerge-most of the low-cost carriers' inefficiencies are confined to the first stage. Results also show a dynamic component, since performance differed across types of airlines during the decade 2000-2010.
\end{abstract}

Key words and phrases: airlines, network DEA.

JEL Classifications: C61, D61, L93

Communications to: Emili Tortosa-Ausina, Departament d'Economia, Universitat Jaume I, Campus del Riu Sec, 12071 Castelló de la Plana, Spain. Tel.: +34 964387168, fax: +34 964728591, e-mail: tortosa@uji.es.

\footnotetext{
${ }^{*}$ Diego Prior and Emili Tortosa-Ausina acknowledge the financial support of Ministerio de Ciencia e Innovación (ECO2013-44115-P and ECO2014-55221-P). Emili Tortosa-Ausina also acknowledges the financial support of Generalitat Valenciana (PROMETEOII/2014/046 and ACOMP/2014/283) and Universitat Jaume I (P1.1B2014-17). The usual disclaimer applies.
} 


\section{Introduction}

Interest in measuring the relative performance of airline companies has developed considerably since the open sky deregulation experience of the US airlines in the late 1970s, which motivated most of the research to focus upon the consequences of this experience in the US. Some studies compared the efficiency differences between the deregulated US airlines and the highly regulated European airlines, which have often been criticized on the grounds that they are inherently less efficient than US carriers (Good et al., 1993). During the last two decades however, the European airline industry has undergone critical restructuring and has evolved from a highly regulated market predominantly operated by national airlines to a dynamic, liberalized industry where airline firms compete freely on prices, routes, and frequencies. Liberalization reforms in the European airline industry created a new market environment which deserves a closer look to find out more about the recent performance record of the airlines.

In this study, we focus on efficiency and productivity issues in the European airline industry post-liberalization over the period between 2000 and 2010. During our study period, a number of factors led to episodes of turbulence in international air transport, such as the $9 / 11$ attacks in 2001 and the global financial crisis which began in 2008. We examine the impact of those major events on the performance of European airlines.

The industry provides an interesting case study since full-service carriers coexist alongside the low-cost carriers that entered the liberalized market after the introduction of the reforms. Compared to US deregulation, liberalization in European airline industry was slow and gradual. Starting in 1987, successive reform packages were introduced to remove economic barriers, with the ultimate aim of establishing a fully liberalized Single Aviation Market. Drastic measures in pricing and market access, however, came with the third liberalization package in 1993, and full deregulation only came into force during 1997. The reforms created a competitive environment which is expected to foster growth in productivity and efficiency. European airlines in the new environment are expected to improve their efficiencies in order to remain competitive. Our paper examines this aspect to find out if there has been any efficiency and productivity change over time.

Few studies in the literature have been devoted solely to analyzing the efficiency and 
productivity of European airlines. Our paper seeks to fill this gap by concentrating on the recent evolution of the performance of airline firms in Europe and specifically analyzing the impact of recent major events on the industry. The great majority of studies do not capture this as they mostly use data from the 1980s or 1990s.

More specifically, we attempt to contribute to this literature in two additional ways. First, we use a unique data set which facilitates capturing recent developments in the industry with more precision. We follow Good et al. (1993), as well as Sickles (1985) and Sickles et al. (1986), to construct our dataset to include all the relevant input and output variables. We use a number of sources, such as the International Civil Aviation Organization (ICAO), Avmark and Platts to construct our comprehensive dataset.

Second, although there are now a remarkable number of studies measuring different aspects of airline efficiency and productivity, there is still scope for more detailed modeling. As we will see in the literature review section, the previous literature dates back as far as the 1970s, when Caves et al. (1983) assessed US airline productivity. More recent empirical contributions have dealt explicitly with airline efficiency issues, generally considering frontier methods. Although some studies have used the parametric Stochastic Frontier Analysis (SFA), they are outnumbered by Data Envelopment Analysis (DEA) applications.

DEA efficiency studies in the airline industry have generally treated their reference technologies as "black boxes", where inputs are transformed into outputs, and the transformation process is generally not modeled explicitly. However, as Färe and Grosskopf (2000) note, in some cases researchers might be interested in adding more structure to the model to better suit the application. Modeling these "black boxes" is the objective of network DEA models. To produce outputs $(y)$, inputs $(x)$ are transformed using the production process $(P)$ i.e., network DEA models aim at disentangling the "black box" or production process $(P)$, which may be quite intricate. Network DEA is also more general than two-stage network structures and, therefore, is more popular due to its ability to accommodate more complex structures. As a consequence, several varieties have been proposed in the literature (see, for instance Färe and Grosskopf, 1996; Färe and Whittaker, 1995).

In the particular case of the airline industry, very few studies have considered two-stage DEA models; of these several have considered the case of airport-not airline - efficiency 
and therefore cannot be strictly regarded as related literature (see, for instance Adler et al., 2013; Yu, 2010). One of the few studies which have explicitly modeled airline performance using a network process is Zhu (2011), who considers fuel, salaries, and other factors in the first stage resources to maintain the fleet size and load factor. The other is Lee and Johnson (2012), who propose a two-dimensional efficiency decomposition (2DED) of profitability for a production system to account for the demand effect observed in productivity analysis. Although these applications deal with related issues, they differ in both the settings and specific models considered. Regarding the time span, Zhu's study covers the years 2007 and 2008 and Lee and Johnson's 2006 to 2008. In contrast, we focus on a longer and more recent period (2000-2010). The selected sample also differs, since while we analyze the European airline industry, Lee and Johnson (2012) look at US airlines, and Zhu (2011), a mix of the two.

However, and most importantly, Zhu (2011) uses the centralized model of Liang et al. (2008), whereas Lee and Johnson (2012) consider network DEA as a part of their study, but not a central part. Specifically, their study considers two parts, and network DEA is only used in the first one to identify four components of efficiency (capacity design, demand generation, operations, and demand consumption), whereas the second dimension decomposes the efficiency measures, integrating them into a profitability efficiency framework. In addition, the application to the airline industry is basically an illustration of their model, whereas in our case it is a central part and the model is particularly tuned to illustrate these issues.

Specifically, we define a network DEA comprising two sub-technologies that can share a portion of the inputs. This proposal opens up an avenue that could be completed in the near future by the study of the advantages of re-allocation of specific inputs, perhaps in the line of Ertay and Ruan (2005) and Ertay et al. (2006). Our work is related to the proposals by Kao and Hwang (2008) and Chen et al. (2009). Although similar, our proposal presents significant variations, however: variable returns to scale as an acceptable technological assumption, shared inputs between the sub-technologies, inclusion of intangible inputs related to customer loyalty and satisfaction, and orientation towards the increase of the final output, and not focusing on averaging the specific efficiency of sub-technologies to define the over- 
all efficiency. Indeed, the additive efficiency decomposition could be of interest in another sector and context, but this is definitely not applicable to the transportation service, as the sole generation of transportation services, without considering the level of use by customers, could never be regarded as a desirable situation.

The paper is organized as follows. After this introduction, the modeling framework and estimation methods are detailed in Section 3. Section 4 gives a brief overview of the data and variables used in the analysis while Section 5 discusses our empirical findings. Section 6 concludes. We also include an appendix in which the construction of the data set, for which we followed Sickles (1985) and Sickles et al. (1986), is presented in detail.

\section{Literature review}

There is now a remarkable number of studies devoted to measuring different aspects related to the efficiency and productivity of airlines. Some early (TFP) applications assessed US airline productivity during the 1970s (Caves et al., 1983). Others examined TFP for international airlines, comparing US airlines under deregulation with non-US airlines (see Forsyth et al., 1986; Caves et al., 1987; Windle, 1991). These early findings, in general, showed an increase in the productive efficiency of US airlines after deregulation, and that US airlines performed better than non-US carriers.

We identify another two broad strands of empirical literature which use frontier methodologies; nonparametric and parametric methods in airline efficiency studies. Among the former, Data Envelopment Analysis (DEA, Charnes et al., 1978) has traditionally been the most popular choice, whereas among the latter Stochastic Frontier Analysis (SFA, Aigner et al., 1977; Meeusen and Van den Broeck, 1977) predominates.

While DEA has the great advantage of being able to handle multiple inputs and outputs more easily, it is criticized for its inability to accommodate either measurement errors or other noise in the data. In contrast, SFA is a parametric methodology that is not subject to these limitations. Unfortunately, SFA also has its drawbacks, the most stringent limitation being that it is subject to the parametric "straitjacket"- since both a functional form for the production function, and the distribution of the efficiencies has to be chosen.

The literature, however, has made progress both in the parametric and nonparametric 
fields - especially the latter (see, for instance Simar and Wilson, 2013). Several comparisons of both strands have appeared in the literature (parametric vs. nonparametric methods), among which we can highlight the recent study by Badunenko et al. (2012). These authors compare the kernel SFA estimator of Fan et al. (1996) with the nonparametric bias-corrected DEA estimator of Kneip et al. (2008), finding conditions under which both estimators would yield similar results. A more recent comparison of DEA and SFA is provided in the bibliometric analysis of Lampe and Hilgers (2015).

In the particular case of the airline industry, several published studies considered both parametric and nonparametric methods. Some studies based on SFA (or other parametric methods) have focused on the case of US airlines (Alam and Sickles, 2000), others have compared the performance of US and European airlines (Good et al., 1993, 1995; Marin, 1998), while others (Barla and Perelman, 1989; Inglada et al., 2006) have compared performance among international airlines; a further group (Ehrlich et al., 1994) deal with the impact of ownership on productivity. ${ }^{1}$

However, airline studies using DEA outnumber those based on SFA, and relevant contributions include Schefczyk (1993), Distexhe and Perelman (1994), Oum and Yu (1995), Coelli et al. (2002), Scheraga (2004), and Barbot et al. (2008), Barros and Peypoch (2009), Bhadra (2009), Merkert and Hensher (2011), to name just a few. Among their main findings, some of the DEA studies confirm that during the 1980s European carriers were technically less efficient than other carriers (Schefczyk, 1993; Distexhe and Perelman, 1994).

As indicated in the introduction, however, some particular variants of DEA are especially suited to dealing with some problems in the airline industry. This is the case of network DEA (Färe and Grosskopf, 2000), whose advantages in this particular field have been highlighted above, and which has no parametric alternative - i.e., the parametric counterpart, "network SFA", does not exist. In addition, it is a promising field of research, as shown by the relatively high number of recent contributions such as, for instance, Avkiran (2015), Fallah-Fini et al. (2015), Huang et al. (2014), Tone and Tsutsui (2014), among which we may also find survey papers (Kao, 2014b). However, despite this expansion, the number of studies focusing on the efficiency of airlines that consider network DEA models are few and relatively recent,

\footnotetext{
${ }^{1}$ From a theoretical point of view, see also Good et al. (1999).
} 
and would include Zhu (2011) and Lee and Johnson (2012).

\section{Methodology}

Estimations of efficiency are usually based on the relationship that can be established between the inputs consumed and the outputs obtained. The estimation method can be very sophisticated, but in most of the cases the technology assumed is extremely simple, as no information is provided about the types of internal processes. These models, in the words of Färe and Grosskopf (2000), treat the production process as a "black box", provided that no information about the internal flow of operations is needed to estimate the efficiency coefficients. An example of this production process, adapted to the airline industry, is presented in Figure 1, where it can been seen that in the airline industry the efficiency assessment requires us to know the $x_{s}$ inputs consumed (i.e., labor, material consumption and capital as fixed inputs) and the $y_{f}$ output (Revenue Tonne Kilometers, $R T K$, which is a standard metric used to quantify the amount of revenue generating payload carried, taking into account the distance flown; RTK s comprise the passengers, freight and mail carried multiplied by the distance flown). In the airline industry, this description is too superficial and does not help to disentangle what the real sources of firms' inefficiencies are.

[Figure 1 about here]

The advantage of the simplicity in this approach is that it can perform the analysis without the need for sophisticated methods. This is the case of the situation presented in Figure 1, which can be assessed by using the conventional DEA methods. So, under the assumption of variable returns to scale, the situation described in Figure 1 can be assessed through the Output-oriented BCC fractional program (Banker et al., 1984):

$$
\begin{aligned}
& \min . \frac{\sum_{s=1}^{S} v_{s} x_{s, t}^{o}-\omega_{o}}{\sum_{f=1}^{F} u_{f} y_{f, t}^{o}} \\
& \text { s.t. } \\
& \frac{\sum_{s=1}^{S} v_{s} x_{s k, t}-\omega_{o}}{\sum_{f=1}^{F} u_{f} y_{f k, t}} \geq 1, \quad k=1, \ldots, K, \\
& u_{f} \geq \epsilon, v_{s} \geq \epsilon .
\end{aligned}
$$


where $u_{f}$ are the output weights, $v_{s}$ the inputs weights, $\omega$ the coefficient indicating the prevailing type of returns to scale and $\epsilon$ is a small non-Archimedean number. As is well known, the objective function includes the observed outputs and inputs corresponding to the DMU under analysis (which is described with the superscript " $O$ ") and the $K$ restrictions refer to each of the DMUs in the sample.

This general model is clearly too limited, which increases the difficulties of understanding the real causes that are generating inefficiency. One good alternative consists of defining the production process and the existent technology in a more detailed way (as presented in Figure 2). In the airline industry, and more generally in the transportation sector, it is useful to separate the production process into two basic stages or sub-technologies. In the first one, firms consume inputs in order to provide a service to their potential customers (say, to offer services in the form of seats-kilometers), but the decision to use the service depends on the organization of the routes, their design and/or the level of customer satisfaction with the level of quality offered in previous travel experiences. Therefore, a separation between the first stage (the production of potential output) from the second (the consumption of the real output) can be established. Zhu's (2000) paper is a precedent for this approach. In his article, when assessing the efficiency of a sample of quoted firms, Zhu refers to two stages, profitability as stage 1 and marketability as stage 2 , where the outputs of stage 1 are the inputs of stage 2 .

[Figure 2 about here]

Consistent with this approach, the two sub-technologies can be assessed separately, which creates specific fractional programs for each sub-technology:

ASSESSMENT OF SUB-TECHNOLOGY 1

$$
\begin{aligned}
& \min . \frac{\sum_{s=1}^{S} v_{s} x_{s, t}^{o}-\omega_{1}}{\sum_{i=1}^{I} w_{i} y_{i, t}^{o}} \\
& \text { s.t. } \\
& \frac{\sum_{s=1}^{S} v_{s} x_{s k, t}-\omega_{1}}{\sum_{i=1}^{I} w_{i} y_{i k, t}} \geq 1, \quad k=1, \ldots, K, \\
& w_{i} \geq \epsilon, v_{s} \geq \epsilon .
\end{aligned}
$$


where $y_{i k, t}$ stands for the $i$ intermediate outputs for the DMU $k$ in time $t$ and $w_{i}$ are the corresponding intermediate output weights.

\section{ASSESSMENT OF SUB-TECHNOLOGY 2}

$$
\begin{aligned}
& \min \cdot \frac{\sum_{i=1}^{I} w_{i} y_{i, t}^{o}-\omega_{2}}{\sum_{f=1}^{F} u_{f} y_{f, t}^{o}} \\
& \text { s.t. } \\
& \frac{\sum_{i=1}^{I} w_{i} y_{i k, t}-\omega_{2}}{\sum_{f=1}^{F} u_{i} y_{f k, t}} \geq 1, \quad k=1, \ldots, K, \\
& u_{f} \geq \epsilon, w_{i} \geq \epsilon .
\end{aligned}
$$

The problem with the separate assessment of each sub-technology is that nothing guarantees that the optimization of the first stage would imply the most suitable solution being achieved for the second stage. In other words, it may well be that the increase in the amount of kilometers in the first stage would not be the best option to increase the number of passengers when, for instance, the issue to be solved in order to improve overall efficiency is the poor level of service quality. If this is the case, a suboptimal allocation of inputs in the first stage can make it difficult to increase the number of satisfied passengers. Summing up, the chained model can provide a suboptimal solution because the inputs consumption can be far from the level desired to achieve the best overall solution.

The use of network DEA can help to overcome these limitations. In this regard, as Kao and Hwang (2008) pointed out, network DEA can be defined by taking the original overall efficiency and introducing the ratios corresponding to the two sub-technologies as additional constraints.

This is precisely what we propose in Figure 3 (the network model for the airline industry) which includes differences from the existing proposals. Our basic assumption of the network model is that the assessment is done inside the "black box", implying that we consider a more detailed description of the process by defining two sub-technologies that share the existent inputs. From the outputs perspective, the network models assume the existence of both intermediate and final outputs. The intermediate outputs are produced in the first stage, which figure as additional inputs in the second stage. From the inputs perspective, our proposal considers the existence of shared inputs between the two sub-technologies, accepting that the target to be achieved is the optimization of the final output. Finally, we 
also assume that, apart from the tangible inputs, there are other intangible inputs related to customer (or to the brand value due to satisfaction with services provided in the past) that can have a decisive influence on the design of the service (first stage), and/or on the customer's decision to use the travel services provided by a specific firm (second stage). The advantage of the network models is that the decision variable to be optimized is the final output (in Figure 3 the $R T K \mathrm{~s}$ ), so the first stage provides an intermediate output that should be consistent with the target of optimizing the efficiency of the second stage.

[Figure 3 about here]

Similarly to Kao and Hwang (2008), our proposed network DEA model consists of introducing the restrictions of the two sub-technologies into the original overall efficiency model, so that the fractional network DEA is defined follows:

NETWORK DEA MODEL CONSIDERING THE TWO SUB-TECHNOLOGIES

$$
\begin{array}{ll}
\min . & \frac{\sum_{s=1}^{S} v_{s} x_{s, t}^{o}+\sum_{f=1}^{F} v_{f} y_{f, t-1}^{o}-\omega_{1}-\omega_{2}}{\sum_{f=1}^{F} u_{f} y_{f, t}^{o}} \\
\text { s.t. } & k=1, \ldots, K, \\
\frac{\sum_{s=1}^{S} v_{s} x_{s k, t}+\sum_{f=1}^{F} v_{f} y_{f k, t-1}-\omega_{1}-\omega_{2}}{\sum_{f=1}^{F} u_{f} y_{f k, t}}, \geq 1 & k=1, \ldots, K, \\
\frac{\sum_{s=1}^{S} v_{s} x_{s k, t}+\sum_{f=1}^{F} v_{f} y_{f k, t-1}-\omega_{1}}{\sum_{i=1}^{I} w_{i} y_{i k, t}} \geq 1, & \\
\frac{\sum_{s=1}^{S} v_{s} x_{s k, t}+\sum_{f=1}^{F} v_{f} y_{f k, t-1}+\sum_{i=1}^{I} w_{i} y_{i k, t}-\omega_{2}}{\sum_{f=1}^{F} u_{f} y_{f k, t}} \geq 1, & k=1, \ldots, K, \\
u_{f} \geq \epsilon, w_{i} \geq \epsilon, v_{s} \geq \epsilon . &
\end{array}
$$

The optimization of this fractional problem requires that, in the optimal solution, the output and the input weights have to be feasible for the overall program as well as for the two sub-technologies. Additionally, it is worth pointing out that the optimal weight of the intermediate output $\left(w_{i}^{*}\right)$ should be exactly the same for the two sub-technologies (in the first as an output and in the second as an input). 
From the previous fractional network DEA problem, it is easy to follow Charnes et al. (1978) to define the multiplier version of the linear program:

$$
\begin{array}{ll}
\min . \sum_{s=1}^{S} v_{s} x_{s, t}^{o}+\sum_{f=1}^{F} v_{f} y_{f, t-1}^{o}-\omega_{1}-\omega_{2} & \\
\text { s.t. } & \\
\sum_{f=1}^{F} u_{f} y_{f, t}^{o}=1, & k=1, \ldots, K, \\
-\sum_{f=1}^{F} u_{f} y_{f k, t}+\sum_{s=1}^{S} v_{s} x_{s k, t}+\sum_{f=1}^{F} v_{f} y_{f k, t-1}-\omega_{1}-\omega_{2} \geq 0, & k=1, \ldots, K, \\
-\sum_{i=1}^{I} w_{i} y_{i k, t}+\sum_{s=1}^{S} v_{s} x_{s k, t}+\sum_{f=1}^{F} v_{f} y_{f k, t-1}-\omega_{1} \geq 0, & \\
-\sum_{f=1}^{F} u_{f} y_{f k, t}+\sum_{s=1}^{S} v_{s} x_{s k, t}+\sum_{f=1}^{F} v_{f} y_{f k, t-1}+\sum_{i=1}^{I} w_{i} y_{i k, t}-\omega_{2} \geq 0, & k=1, \ldots, K, \\
u_{f} \geq \epsilon, w_{i} \geq \epsilon, v_{s} \geq \epsilon . &
\end{array}
$$

From the primal program (the multiplier version) the dual version (the envelopment version) expresses the output-oriented network DEA model with variable returns to scale:

$$
\begin{array}{ll}
\max . \beta_{t}, & \\
\text { s.t. } & \\
\sum_{k=1}^{K} \lambda_{k} x_{s k, t} \leq x_{s, t}^{o}, & s=1, \ldots, S, \\
\sum_{k=1}^{K} \lambda_{k} y_{f k, t-1} \leq y_{f, t-1}^{o}, & f=1, \ldots, F, \\
\sum_{k=1}^{K} \lambda_{k} y_{i k, t} \geq y_{i, t}^{o} \alpha_{t}, & i=1, \ldots, I, \\
\sum_{k=1}^{K} \lambda_{k}=1, & \\
\sum_{k=1}^{K} \mu_{k} x_{s k, t} \leq x_{s, t}^{o}, & s=1, \ldots, S, \\
\sum_{k=1}^{K} \mu_{k} y_{f k, t-1} \leq y_{f, t-1}^{o}, & f=1, \ldots, F, \\
\sum_{k=1}^{K} \mu_{k} y_{i k, t} \leq y_{i, t}^{o} \alpha_{t}, & i=1, \ldots, I, \\
\sum_{k=1}^{K} \mu_{k} y_{f k, t} \geq y_{f, t}^{o} \beta_{t}, & f=1, \ldots, F, \\
\sum_{k=1}^{K} \mu_{k}=1, & \\
\lambda_{k} \geq 0, \mu_{k} \geq 0 . &
\end{array}
$$

where $\beta_{t}$ is the output-oriented network efficiency coefficient for the unit under analysis in period $t$. For the purposes of this study $\beta_{t}$ represents the firm's performance level related to the final output $R T K_{(t)}$. The term $\beta_{t}=1$ indicates that the DMU (Decision Making Unit, in our case the airline company) under analysis is efficient, and $\beta_{t}>1$ indicates that the DMU is inefficient - the greater the $\beta_{t}$, the more inefficient the DMU is in generating 
revenues (to reduce the scope of values, in the empirical section the results are presented in terms of the inverse of the efficiency coefficient). $y_{i, t}$ is the intermediate output vector of the DMU under analysis in period $t$ (we have one intermediate output: the service offered, and $\alpha_{t}$ is the required change associated with the intermediate output consistent with the maximization of the final output, not a desirable objective in itself), $x_{s, t}^{o}$ is the observed level of shared inputs (material consumption, labor and capital) vector of the DMU under analysis in period $t$ that are required in both the first and the second stages and $y_{f, t-1}^{o}$ represents the market intangible assets generated up to the previous year $t-1$. These intangible assets can be related to the brand value and to the customer satisfaction that increases the level of customer loyalty, and are represented by the variable $R T K_{(t-1)}$. Finally, $y_{f k, t}, y_{i k, t}, x_{s k, t}$, $y_{f k, t-1}$, refer to final and intermediate outputs, shared inputs and market intangible inputs vectors for the $k(k=1, \ldots, K)$ DMUs forming the total sample, and $\lambda$ and $\mu$ indicate the activity vector.

As previously mentioned, in contrast to "standard" DEA proposals, this program has different steps, which are solved simultaneously. Step 1 coincides with the restrictions formed with the $\lambda$ vector, and step 2 includes the remaining restrictions, built with the $\mu$ vector as the activity vector.

Previous studies in the field of network DEA include Färe and Grosskopf (1996, 2000), Sexton and Lewis (2003), Lewis and Sexton (2004), Prieto and Zofío (2007), Tone and Tsutsui (2009), and Angulo-Ruiz et al. (2014). In the particular case of slacks-based measures, Kao (2014a) has recently proposed a model in the context of network DEA, showing that the network model has stronger properties than its conventional "black box" counterpart. Our proposal extends the existing proposals in the sense that: (i) shared inputs are taken into account not only for the optimization of the intermediate output but also for the final output; and (ii) the optimization of steps 1 and 2 is produced simultaneously to maximize the final output, as the isolated optimization of step 1 (the chained model of Figure 2) does not guarantee the achievement of the maximum output in step 2.

Our proposal is also related to the recent works by Kao and Hwang (2008) and Chen et al. (2009). With regard to the work of Kao and Hwang (2008), the theoretical development is similar, although our technology assumes the presence of variable returns to scale, while 
constant returns to scale is the only assumption made by these authors. Other differences consist of the presence of shared inputs in the two sub-technologies and the consideration of temporal intangible inputs, which makes our proposal closer to the industry under scrutiny. The work by Chen et al. (2009) differs from ours in the notion of efficiency under assessment. Thus, while our proposal emphasizes the efficiency in terms of the final output, Chen et al. (2009) define an additive efficiency decomposition of the overall efficiency in the two subtechnologies.

\section{Data and variables}

Our sample is comprised of 87 airlines from 23 European countries during the period 20002010. The data is obtained from various sources: (i) the International Civil Aviation Organization (ICAO) (airline financial, personnel, traffic and fleet data); (ii) Platts (fuel prices); (iii) AVMARK (historic market value per aircraft model); (iv) Economic and Social Data Services (ESDS) and (v) International Financial Statistics (IFS) (gross fixed capital formation at both current and constant prices); (vi) Bloomberg (the interest rate on Baa bonds for USA carriers); (vii) Penn World Tables (PPPI).

The first of our inputs is flight capital $(K)$, which we measure using the number of aircrafts per airline. This information is provided by ICAO fleet data, which reports the number of aircrafts owned by each airline at the beginning of the year, the aircrafts bought/sold (retired) during the year, and the number of aircrafts owned at the end of the year. The variable is calculated as the sum of the number of aircrafts at the beginning and the end of the year divided by two. The second input is the labor Index $(L)$; this is a multilateral Törnqvist-Theil index constructed using the number of pilots, cabin crew, mechanics, aircraft handlers, and other labor by considering the mid-year count of full-time equivalent personnel in each category weighted by the annual expenses relevant to each category. The third input is the material quantity index $(M I)$, a multilateral Törnqvist-Theil index, composed of the quantity of non-flight equipment, quantity of other materials, quantity of fuel, and quantity of landing services. We constructed our input and output quantities following the approach recommended by Sickles (1985) and Sickles et al. (1986). Full details on the construction of the input quantities have been deferred to the Appendix. 
The output variable is the quantity of revenue output ( $R T K$, revenue ton kilometers). $R T K$ is a standard metric used in the airline industry and the literature to quantify the amount of revenue generating payload carried, taking into account the distance flown; RTK is comprised of the passengers, freight and mail carried multiplied by the distance flown.

The description of the input and output variables is reported in Table 1. Summary statistics for all variables are reported in Table 2 and, as can be observed, differences in size are substantial (the biggest firm has 429 aircrafts while the smallest just 1). These considerable differences have been taken into account and, as a result, program (6) has been defined assuming variable returns to scale for the two sub-technologies. The list of airline companies in the sample is reported in Table 3.

[Table 1 about here]

[Table 2 about here]

[Table 3 about here]

\section{Results}

The results of applying model (6) to our data are presented in Tables 4, 5 and 6 . In each of these tables we report summary statistics for the different stages of the production process, including intermediate $(\alpha)$ as well as final $(\beta)$ efficiencies. We also split the results for pre-crisis (2000-2007) and crisis years (2008-2010), as well as all years (2000-2010). In addition, we explore some of the likely sources of heterogeneity, providing results for low-cost and full-service airlines (Table 5) as well as airlines from European Union (EU) countries, considering the EU membership as of 1995 (i.e., what is usually referred to as EU15) plus Switzerland and Iceland (Table 6).

[Table 4 about here]

[Table 5 about here]

[Table 6 about here] 


\subsection{General efficiency trends}

Table 4 shows that, in general, much of the inefficiency is generated in the first stage of the analysis. Compared with the final efficiencies $(\beta)$, the values corresponding to the summary statistics of the intermediate efficiency scores $(\alpha)$ show values which are relatively similar, implying that they would explain much of the final efficiency. Therefore, efforts to reduce inefficiencies should be concentrated mainly in the first stage of the production process, and some reallocations of inputs and outputs could be considered. Taking into account the entire period (2000-2010), the average efficiency is particularly low (60.81\%), indicating that inefficiencies could be reduced by almost $40 \%$ - on average. The value corresponding to the median is slightly higher $(64.29 \%)$, which could imply that the results are partly driven by relatively low performing airlines. This would occur because the existence of airlines whose efficiencies are low would push the average downwards, but would affect the median less seriously - unless there were many low-performing airlines. The results corresponding to the intermediate efficiencies $(\alpha)$ for the entire 2000-2010 period suggest that, considering both the mean and the median, a non-negligible amount of inefficiencies is generated in the second stage of the analysis. The median intermediate efficiency score (72.26\%), compared with the final efficiency (64.29\%) indicates that, although median efficiency in the second stage is relatively high, some reallocations between the different stages (if possible) might increase the efficiency of the production process.

We also report results for both periods, considering pre-crisis (2000-2007) and crisis years (2008-2010). Although, on average, results are relatively close (the final efficiency is $61.29 \%$ in the pre-crisis years and $59.39 \%$ in the crisis years), there are larger discrepancies when focusing on other summary statistics such as the median, whose values for the final efficiency are $66.58 \%$ and $59.69 \%$ for $2000-2007$ and 2008-2010, respectively. However, in the case of the efficiencies corresponding to the first stage of the "black box", the median values for both periods are quite similar $(72.31 \%$ for the pre-crisis and $72.22 \%$ for the crisis years), which indicates that some of the most inefficient airlines' performance is also particularly poor in the second stage. Again, the discrepancies between the median and the mean might be driven by particularly low-performance airlines, whose low efficiencies push the mean downwards. 
Although the analysis of the median enables a better understanding of the underlying tendencies, these are only two summary statistics that conceal a great deal of information. The structure of the data can be unveiled with more precision by focusing on the densities corresponding to the efficiency scores, both intermediate and final, which are provided in Figures 4 and 5. The densities have been estimated nonparametrically using kernel smoothing methods and, in the case of the final efficiencies, we considered the reflection method (Silverman, 1986) in order to "reflect" the probability mass beyond 1 (since $\beta \in(0,1]$ there should be no probability mass beyond 1). Both figures, especially 4, reveal some tendencies concealed by summary statistics - not only the mean and the median but also the standard deviation. In particular, there is a remarkable amount of multi-modality, with two prominent modes at both tails of the distribution of $\beta$ s, especially at the beginning of the period (Figure 4a). Although the emergence of one of these modes was to be expected, since it corresponds to the efficient airlines, with a value of 1 , the prominent mode in the vicinity of 0.15 in Figure 4a reveals a strikingly high number of quite inefficient airlines. Although these pockets of poor performance have been smoothed away over time, disparities still exist by the end of the 2000s (Figure 4c).

[Figure 4 about here]

[Figure 5 about here]

In the case of the intermediate efficiencies, whose densities are shown in Figure 5, the multi-modality is still present, although the fact that some values for $\alpha$ are actually higher than 1 results in a slight fraction of probability mass lying above 1 . However, the disparate performances persist, implying that the second stage does actually exacerbate some of the inefficiencies found in the first stage of the analysis.

\subsection{Exploring efficiency differentials}

We provide some insights on the likely sources of inefficiency by splitting results for low-cost vs. full-service airlines, and EU15 (plus Iceland and Switzerland) vs. non-EU15 airlines. Results are reported in Table 5 and Figure 6, for low-cost vs. full-service airlines, and in Table 6 and Figure 7 for EU15 vs. non-EU15 airlines. 
[Figure 6 about here]

[Figure 7 about here]

\subsubsection{Low-cost vs. full-service airlines' efficiencies}

In the first of the comparisons (low-cost vs. full-service airline efficiencies), which also merits a study in its own right, in general the differences are notable. However, the analysis by subperiods is pertinent in this particular case, since the discrepancies increased during the crisis years. As indicated in Table 5, when either the median or the average is considered, the lowcost airlines outperform their full-service counterparts during the pre-crisis years. During the crisis years these differences have widened substantially - the median final efficiency for the low-cost airlines is $83.70 \%$, whereas for full-service carriers it is $56.66 \%$.

In addition, for the low-cost airlines, the second stage of the evaluation process is very efficient and, considering the entire period (2000-2010), the values corresponding to the median for the two stages of the evaluation are almost the same $(75.28 \%$ and $74.89 \%$ for the intermediate and final efficiencies, respectively). This is also apparent in Figure 6, where the solid lines in both sub-figures (Figures 6a and 6b), corresponding to the low-cost airlines are similar (except for the probability mass beyond 1). These facts indicate that the low-cost firms have adapted much more quickly to the economic downturn, and that most of the inefficiencies correspond to the full-service carriers, as shown by the notable bump of the dotted line in the vicinity of 0.2 (Figure $6 \mathrm{~b}$ ).

\subsubsection{European Union vs. non European Union membership}

We also report results according to European Union membership (Table 6 and Figure 7), although EU membership is defined previous to 2004, and also includes Iceland and Switzerland. We therefore define as European Union countries those members up to 1995 (i.e., EU15) plus Iceland and Switzerland (we will refer to this group as EU15+IS), whereas the rest of the countries are classified as non-EU. We consider this classification in order to analyze how the airlines from countries that had just joined the EU, and which faced different competitive conditions and technologies, perform in terms of efficiency compared to their 
EU counterparts. If their efficiency levels differed substantially this might thwart the future viability of airlines in non-EU15 countries.

Summary statistics considering this classification are reported in Table 6. They reveal that discrepancies do exist between the two groups, and are notable. Considering the entire period (2000-2010), the average final efficiency corresponding to EU15+IS airlines almost doubles that for non-EU airlines (68.27\% vs. $36.63 \%)$; in the case of the median, it is actually more than double ( $77.67 \%$ vs. $30.83 \%)$, suggesting that most of the airlines in non-EU15 country group are quite inefficient. In this sense, the higher value of the mean compared with that for the median might be due to some airlines in these countries catching up faster with their peers in EU countries.

This catching-up effect for non-EU15 airlines actually exists, since results differ for the two sub-periods. Whereas in 2000-2007 the average final efficiency is $33.75 \%$, during $2008-$ 2010 it is $42.95 \%$, and the increase is even wider when considering the median (from $24.78 \%$ to $37.34 \%$ ). In contrast, for EU15 airlines the tendency is for the final efficiency to worsen (the median decreases from $78.73 \%$ to $71.80 \%$ ), suggesting that airlines from these countries have been most affected by the crisis.

The profound differences among airlines in the EU15+IS group and the rest is more apparent in Figure 7. Regarding the final efficiencies, most airlines in non-EU countries are particularly inefficient (the highest amount of probability mass concentrates under 0.4), whereas for their EU peers results are just the opposite. The intermediate efficiencies (Figure 7a) suggest a large fraction of the inefficiencies were generated in the first stage of the analysis, although a non-negligible share emerged in the second stage. This would suggest that reallocations, if possible, could only marginally contribute to guarantee the viability of the most inefficient airlines.

\section{Conclusions}

The main drivers of success in the airline industry are customer satisfaction, cost minimization and efficient route system. An airline wishing to maintain higher market share and profitability should aim to excel at least in these three dimensions. However, steering an airline company towards success is far from easy given the increasing competition in the 
industry over the last two decades. In particular, the European airline industry has undergone a significant transformation from being highly regulated to a fairly liberalized industry through what is called open sky competition policy. The liberalization of the airline industry that took place during the 1990s in Europe allowed airlines to compete freely on prices, routes and frequencies.

The competitive environment created as a result of liberalization has stimulated industry players to seek innovative approaches to minimize costs and better utilize assets in order achieve superior customer satisfaction than their peers. The arrival of low-cost carriers to the industry has further stirred up competition in Europe and, consequently, put pressure on the legacy carriers, or full-service carriers, to improve their performance, service quality and minimize costs. The airline industry has also frequently been subject to external shocks that have shaped its future (among others, the 9/11 attack, European Union expansion, fluctuations in the international fuel prices, and the global financial crisis in the late 2000s) and imposed further pressure on the market players. The fierce competition and the impact of external shocks have pushed the full-service carriers to switch their business models towards re-routing and re-fleeting to maintain high customer satisfaction levels. This was achieved by flying the latest models of aircrafts on the new routes as opposed to past practices of using old and cheap models on new routes.

The vibrant environment in which European air carriers now operate opens up many research questions to be explored that will enrich the literature for many years to come. This paper has focused on an important and imperative feature of the airline industry, which belongs to the league of capital intensive industries, namely, measuring its performance, although with some notable differences. In previous studies analyzing air carriers' performance, either in Europe or in other contexts, estimations were based on the relationship between the inputs consumed and the outputs obtained. Despite the relevance of most of these studies, the technology applied was generally simple, since no information on the types of internal processes is provided - these are models that treat the production process as a "black box". A better way to approach this issue is to describe the production process in an enhanced model, which in the case of the airline industry implies considering two basic stages. In the first one, airlines consume inputs in order to provide a service (such as seats- 
kilometers), and in the second one the decision to use the service provided depends on the organization and design of the airlines, or the level of customer satisfaction with the level of quality offered in their previous travel experiences. This implies that a separation between the first stage (the production of potential output) from the second (the consumption of the real output) should, ideally, be established.

This is the rationale that usually underlies most network DEA proposals but, to date, applications in the airline industry have been extremely scant. We have attempted to fill this gap, by proposing a network model that has several novelties with respect to the existing literature. Regarding the outputs, we assume the existence of both intermediate outputs (which are obtained in the first stage, but operate as an additional input in the second stage) and final outputs. Regarding the inputs, they can be specific to the stage we are in (as the assumption is to share the inputs between the two sub-technologies) and, in addition, there are intangible inputs related to customer loyalty or brand value due to the services provided in previous years.

The results can be explored from multiple angles. The two-stage analysis reveals that a remarkable amount of inefficiency is generated in the second stage of the analysis. However, inefficiencies generated in the first stage predominate, which implies that they can be reduced to a limited extent by reallocating inputs. In addition, this finding is not generalized - either across firms or over time. Regarding the former, we find that low-cost carriers are more efficient than their full-service peers. Yet increasing efficiency by reallocating resources is easier for legacy carriers, since in this case inefficiencies emerge at both stages of the production process. Taking the temporal dimension into account, the findings of this research suggest that, regardless of the stage of the production process considered, airlines in different groups have had disparate performance levels. Low-cost carriers are adapting more quickly to the new economic scenario that emerged after the onset of the crisis in 2007-08. In addition, airlines from European Union countries (previous to the enlargements of the 2000s, plus Iceland and Switzerland) are much more efficient than the rest, although a slow catching-up process is also taking place.

These results are also interesting because, apart from having considered a relevant methodology in an industry undergoing rapid change, we also used a very comprehensive 
data construction by following Sickles (1985), Sickles et al. (1986) and Good et al. (1993). This detailed information on inputs and outputs is not always available in performance assessment studies and, therefore, in our case conclusions can be considered particularly strong.

\section{References}

Adler, N., Liebert, V., and Yazhemsky, E. (2013). Benchmarking airports from a managerial perspective. Omega, 41(2):442-458.

Aigner, D., Lovell, C. A. K., and Schmidt, P. (1977). Formulation and estimation of stochastic frontier production models. Journal of Econometrics, 6:21-37.

Alam, I. M. S. and Sickles, R. C. (2000). Time series analysis of deregulatory dynamics and technical efficiency: the case of the US airline industry. International Economic Review, 41(1):203-218.

Angulo-Ruiz, F., Donthu, N., Prior, D., and Rialp, J. (2014). The financial contribution of customer-oriented marketing capability. Journal of the Academy of Marketing Science, forthcoming.

Avkiran, N. K. (2015). An illustration of dynamic network DEA in commercial banking including robustness tests. Omega, forthcoming.

Badunenko, O., Henderson, D. J., and Kumbhakar, S. C. (2012). When, where and how to perform efficiency estimation. Journal of the Royal Statistical Society, Series A (Statistics in Society), 175(4):863-892.

Banker, R. D., Charnes, A., and Cooper, W. W. (1984). Some models for estimating technical and scale inefficiencies in Data Envelopment Analysis. Management Science, 30:1078-1092.

Barbot, C., Costa, A., and Sochirca, E. (2008). Airlines performance in the new market context: A comparative productivity and efficiency analysis. Journal of Air Transport Management, 14:270-274. 
Barla, P. and Perelman, S. (1989). Technical efficiency in airlines under regulated and deregulated environments. Annals of Public and Cooperative Economics, 60:103-124.

Barros, C. P. and Peypoch, N. (2009). An evaluation of European airlines' operational performance. International Journal of Production Economics, 122(2):525-533.

Bhadra, D. (2009). Race to the bottom or swimming upstream: performance analysis of US airlines. Journal of Air Transport Management, 15(5):227-235.

Caves, D. W., Christensen, L. R., and Tretheway, M. W. (1983). Productivity performance of US trunk and local servce airlines in the era of deregulation. Economic Inquiry, 21(3):312324.

Caves, D. W., Christensen, L. R., Tretheway, M. W., and Windle, R. J. (1987). An assessment of the efficiency effects of US airline deregulation via an international comparison. In Bailey, E. E., editor, Public Regulation, New Perspectives on Institutions and Policies. MIT Press.

Charnes, A., Cooper, W. W., and Rhodes, E. (1978). Measuring the efficiency of decision making units. European Journal of Operational Research, 2(6):429-444.

Chen, Y., Cook, W. D., Li, N., and Zhu, J. (2009). Additive efficiency decomposition in two-stage DEA. European Journal of Operational Research, 196(3):1170-1176.

Coelli, T., Grifell-Tatjé, E., and Perelman, S. (2002). Capacity utilisation and profitability: A decomposition of short-run profit efficiency. International Journal of Production Economics, 79:261-278.

Distexhe, V. and Perelman, S. (1994). Technical efficiency and productivity growth in an era of deregulation: the case of airlines. Swiss Journal of Economics and Statistics, 140:669-689.

Ehrlich, I., Gallais-Hamonna, G., Liu, Z., and Lutter, R. (1994). Productivity growth and firm ownership: an analytical and empirical investigation. Journal of Political Economy, 102:1006-1038. 
Ertay, T. and Ruan, D. (2005). Data envelopment analysis based decision model for optimal operator allocation in CMS. European Journal of Operational Research, 164(3):800-810.

Ertay, T., Ruan, D., and Tuzkaya, U. (2006). Integrating data envelopment analysis and analytic hierarchy for the facility layout design in manufacturing systems. Information Sciences, 176(3):237-262.

Fallah-Fini, S., Triantis, K., Rahmandad, H., and de la Garza, J. M. (2015). Measuring dynamic efficiency of highway maintenance operations. Omega, 50:18-28.

Fan, Y., Li, Q., and Weersink, A. (1996). Semiparametric estimation of stochastic production frontier models. Journal of Business and Economic Statistics, 14:460-468.

Färe, R. and Grosskopf, S. (1996). Productivity and intermediate products: a frontier approach. Economics Letters, 50(1):65-70.

Färe, R. and Grosskopf, S. (2000). Network DEA. Socio-Economic Planning Sciences, $34(1): 35-49$.

Färe, R. and Whittaker, G. (1995). An intermediate input model of dairy production using complex survey data. Journal of Agricultural Economics, 46(2):201-213.

Forsyth, P. J., Hill, R. D., and Trengove, C. D. (1986). Measuring airline efficiency. Fiscal Studies, 7:61-81.

Good, D. H., Nadiri, M. I., Roller, L.-H., and Sickles, R. H. (1993). Efficiency and productivity growth comparison of European and US air carriers: a first look at the data. Journal of Productivity Analysis, 4:115-125.

Good, D. H., Nadiri, M. I., and Sickles, R. C. (1999). Index number and factor demand approaches to the estimation of productivity. In Pesaran, M. H. and Schmidt, P., editors, Handbook of Applied Econometrics, volume II of Microeconomics. Wiley-Blackwell, New York.

Good, D. H., Roller, L.-H., and Sickles, R. (1995). Airline efficiency differences between Europe and the US: implications for the pace of EC integration and domestic regulation. European Journal of Operational Research, 80:508-518. 
Huang, C., Ho, F., and Chiu, Y. (2014). Measurement of tourist hotel' productive efficiency, occupancy, and catering service effectiveness using a modified two-stage DEA model in Taiwan. Omega, 48:49-59.

Inglada, V., Rey, B., Rodríguez-Álvarez, A., and Coto-Millán, P. (2006). Liberalisation and efficiency in international air transport. Transportation Research Part A, 40:95-105.

Kao, C. (2014a). Efficiency decomposition in network Data Envelopment Analysis with slacks-based measures. Omega, forthcoming.

Kao, C. (2014b). Network data envelopment analysis: A review. European Journal of Operational Research, 239(1):1-16.

Kao, C. and Hwang, S.-N. (2008). Efficiency decomposition in two-stage data envelopment analysis: An application to non-life insurance companies in taiwan. European Journal of Operational Research, 185(1):418-429.

Kneip, A., Simar, L., and Wilson, P. W. (2008). Asymptotics for DEA estimators in nonparametric frontier models. Econometric Theory, 24:1663-1697.

Lampe, H. W. and Hilgers, D. (2015). Trajectories of efficiency measurement: A bibliometric analysis of DEA and SFA. European Journal of Operational Research, 240:1-21.

Lee, C.-Y. and Johnson, A. L. (2012). Two-dimensional efficiency decomposition to measure the demand effect in productivity analysis. European Journal of Operational Research, 216(3):584-593.

Lewis, H. F. and Sexton, T. R. (2004). Network DEA: efficiency analysis of organizations with complex internal structure. Computers $\&$ Operations Research, 31(9):1365-1410.

Liang, L., Cook, W. D., and Zhu, J. (2008). DEA models for two-stage processes: Game approach and efficiency decomposition. Naval Research Logistics, 55(7):643-653.

Marin, P. L. (1998). Productivity differences in the airline industry: partial deregulation versus short run projection. International Journal of Industrial Organization, 16:395-414. 
Meeusen, W. and Van den Broeck, J. (1977). Efficiency estimation from Cobb-Douglas production functions with composed error. International Economic Review, 18(2):435444.

Merkert, R. and Hensher, D. A. (2011). The impact of strategic management and fleet planning on airline efficiency-A random effects Tobit model based on DEA efficiency scores. Transportation Research Part A: Policy and Practice, 45(7):686-695.

Oum, T. H. and Yu, C. (1995). A productivity comparison of the world's major airlines. Journal of Air Transport Management, 2:181-195.

Prieto, A. M. and Zofío, J. L. (2007). Network DEA efficiency in input-output models: With an application to OECD countries. European Journal of Operational Research, 178(1):292-304.

Schefczyk, M. (1993). Operational performance of airlines: an extension of traditional measurement paradigms. Strategic Management Journal, 14:301-317.

Scheraga, C. A. (2004). Operational efficiency versus financial mobility in the global airline industry. Transportation Research Part A, 38:383-404.

Sexton, T. R. and Lewis, H. F. (2003). Two-stage DEA: An application to major league baseball. Journal of Productivity Analysis, 19(2-3):227-249.

Sheather, S. J. and Jones, M. C. (1991). A reliable data-based bandwidth selection method for kernel density estimation. Journal of the Royal Statistical Society, Ser.B,53(3):683690.

Sickles, R. C. (1985). A nonlinear multivariate error components analysis of technology and specific factor productivity growth with an application to the US airlines. Journal of Econometrics, 27(1):61-78.

Sickles, R. C., Good, D., and Johnson, R. L. (1986). Allocative distortions and the regulatory transition of the US airline industry. Journal of Econometrics, 33(1):143-163.

Silverman, B. W. (1986). Density Estimation for Statistics and Data Analysis. Chapman and Hall, London. 
Simar, L. and Wilson, P. W. (2013). Estimation and inference in nonparametric frontier models: Recent developments and perspectives. Foundations and Trends in Econometrics, $5: 183-337$.

Tone, K. and Tsutsui, M. (2009). Network DEA: a slacks-based measure approach. European Journal of Operational Research, 197(1):243-252.

Tone, K. and Tsutsui, M. (2014). Dynamic DEA with network structure: A slacks-based measure approach. Omega, 42:124-131.

Windle, R. J. (1991). The world's airlines: a cost and productivity comparison. Journal of Transport Economics and Policy, 25:31-49.

Yu, M.-M. (2010). Assessment of airport performance using the SBM-NDEA model. Omega, 38(6):440-452.

Zhu, J. (2000). Multi-factor performance measure model with an application to Fortune 500 companies. European Journal of Operational Research, 123:105-124.

Zhu, J. (2011). Airlines performance via two-stage network DEA approach. Journal of CENTRUM Cathedra - The Business and Economics Research Journal, 4(2):260-269.

\section{Appendix: Data construction}

The input variables are constructed following the approach by Sickles (1985) and Sickles et al. (1986). This is also a significant contribution of the paper, since it provides very detailed information on airline industry data but, to date, the number of studies using these methods is relatively low. The inputs are constructed as follows:

Quantity of capital $(K)$ : quantity of flights (fleet data ICAO), namely,

$$
\text { QFlights }=\frac{\text { QBeginning }+ \text { QEnd }}{2}
$$

Labor Quantity Index $(L)$ : the information on personnel count and expenses (i.e., salaries) we obtain from the ICAO. The labor input is an aggregate of four separate categories, 
namely: (i) pilots, co-pilots, and others; (ii) flight attendants; (iii) mechanics; and (iv) ticketing and sales. For all these categories the expenses $(E X P)$ are the salaries, whereas the quantities $(Q)$ correspond to the mid-year count. The quantity labor index will then be defined as:

$$
\text { Quantity Labor Index }=\sum \varphi_{i} \times Q_{i}
$$

where $\varphi_{i}$ is the weight of each personnel category expenses relative to total personnel expenses:

$$
\varphi_{i}=\frac{\text { Personnel category } \text { Cost }_{i}}{\sum \text { All Personnel Cost }}
$$

Quantity of materials $(M I)$ : the quantity of materials is a Divisia index composed of four main input quantities, mainly the quantity of non-flight equipment, other materials and fuel.

The material quantity index, $M I$, is defined as follows:

Material quantity index $(M I)=\sum\left[\left(W_{1} \times Q F u e l\right),\left(W_{2} \times Q N F E\right),\left(W_{3}\right.\right.$

$\times$ QOtherMaterials $),\left(W_{4}\right.$

$\times$ Qlandingservices $)]$

Where $W_{1}, W_{2}, W_{3}$ and $W_{4}$ are weights of each quantity, weighted by each item expenses to the total expenses.

We will consider the following as these four materials:

A. Non-flight equipment $(N F E)$ : in order to obtain the quantity of $N F E$ we need to obtain an economic price index for $N F E$ which we use to deflate the expenses of non-flight equipment as follows:

$$
\text { Quantity } N F E_{i}=\frac{\text { Annual } N F E}{\left(\omega_{i}^{\prime}+\lambda\right) \times X \times \zeta_{k i}}
$$

where: 
- $\zeta_{k i}$ is the implicit deflator for GFCF from each country, obtained from ESDS data, i.e.:

$$
\zeta_{k i}=\frac{\text { Gross Fixed Capital Formation at Current Prices }(G F C F)}{\text { Gross Fixed Capital Formation at Constant Prices }}
$$

- $\lambda$ is the equivalent annual depreciation rate for $N F E=6.667 \%$, "the assumption of 15 years expected life of NFE".

- $\omega_{i}^{\prime}$ is the adjusted price of capital calculated as follows:

$$
\omega_{i}^{\prime}=(1+\omega) \times X \times\left(1+\gamma_{i}\right)-1
$$

- $\omega$ is the interest rate for long-term bonds, i.e. "it is the interest rate on Baa bonds for USA carriers" (Bloomberg).

- $\gamma$ is the country risk premium for T-bond above the USA T-bond calculated as follows:

$$
\gamma_{\text {risk premium }}=\left(\frac{1+\operatorname{country}_{i} T-\text { bond rate }}{1+\text { USAT }- \text { bond rate }}\right)-1
$$

(country T-bond rate and USA T-bond rate are provided by Bloomberg).

B. Other materials $(M)$ : other material expenses, includes expenditure on supplies, services, and ground capital equipment which are combined into a residual aggregate. Since the data are all in US dollars we use the purchasing power of one dollar or, if its market exchange rate equivalent is not the same in all countries, we use the purchasing power parity PPP exchange rate. Its quantity is calculated as:

$$
M_{i}=\frac{\text { Annual Expenses }_{U S D}}{P P P I_{i}}
$$

where $i$ is the country index, and the price is PPPI (obtained from the Penn World Tables).

C. Fuel $(F)$ : expenses of fuel from ICAO. The airline jet-fuel prices are estimated as the weighted average of the domestic fuel prices in Europe weighted by the 
domestic performed tonne-kilometre added to the international jet-fuel prices weighted by international performed tonne-kilometer. This approach explicitly distinguishes between the cost of fuel for international flights and domestic flights. The Jet-Fuel price is expressed in USD per barrels hence the quantity is in barrel. All information on fuel prices is provided by Platts.

$$
Q=\frac{\text { Fuel expenses }}{\text { Weighted fuel price }}
$$

D. Quantity of landing services: the quantity of landing services is represented by the number of aircraft departures (ICAO). 
Table 1: Description of the inputs, output and control variables

\begin{tabular}{|c|c|c|c|c|}
\hline & Variable & Variable name & Definition & Source/measurment \\
\hline \multirow{3}{*}{ Inputs } & $K$ & Capital (flight capital) & \# of aircrafts & Fleet data (ICAO), AVMARK \\
\hline & $L$ & Labour & $\begin{array}{l}\text { Quantity of pilots, cabin crew, mechan- } \\
\text { ics, passenger and aircraft handlers, } \\
\text { and other labour (Divisia index) }\end{array}$ & Personnel data (ICAO) \\
\hline & $M I$ & Materials & $\begin{array}{l}\text { Quantity of supplies, outside services, } \\
\text { and non-flight equipment (Divisia in- } \\
\text { dex) }\end{array}$ & $\begin{array}{l}\text { Traffic and financial data (ICAO, } \\
\text { Bloomberg, ESDS, IFS, Platts) }\end{array}$ \\
\hline Intermediate output & $R T K /(L O A D F A C T O R)$ & Services offered & $R T K /$ LOAD FACTOR & ICAO, AVMARK \\
\hline Final output & $R T K$ & Revenue output & Revenue ton kilometres & ICAO \\
\hline
\end{tabular}


Table 2: Summary statistics on inputs and outputs

\begin{tabular}{|c|c|c|c|c|c|c|c|c|}
\hline & Variable & Mean & Std.dev. & Min. & $1^{\text {st }}$ quartile & Median & $3^{\text {rd }}$ quartile & Max. \\
\hline \multirow{3}{*}{ Inputs } & $K$ & 44.34 & 72.17 & 1.0 & 7.0 & 19.0 & 44.0 & 429.5 \\
\hline & $L$ & $1,688.61$ & $3,981.84$ & 4.29 & 76.32 & 302.46 & $1,064.31$ & $28,367.04$ \\
\hline & $M I$ & $352,542.57$ & $684,635.59$ & 121.80 & $19,971.97$ & $70,597.67$ & $313,405.04$ & $3,584,498.04$ \\
\hline \multirow{2}{*}{$\begin{array}{l}\text { Intermediate output } \\
\text { Final output }\end{array}$} & $R T K /(L O A D F A C T O R)$ & $2,606,015.16$ & $5,693,738.08$ & 329.18 & $90,920.42$ & $422,010.61$ & $1,711,816.35$ & $29,601,644.44$ \\
\hline & $R T K$ & $1,754,432.86$ & $3,900,195.21$ & 132.00 & $50,762.00$ & $235,202.00$ & $1,227,710.00$ & $21,313,184$ \\
\hline
\end{tabular}


Table 3: List of airlines in the sample (incomplete panel)

\begin{tabular}{|c|c|c|}
\hline ID & Country & Company \\
\hline 1 & ARMANIA & ARMAVIA \\
\hline 2 & AUSTRIA & AUSTRIAN AIRLINES \\
\hline 3 & CROATIA & CROATIA AIRLINES \\
\hline 4 & CZECH REPUBLC & CZECH AIRLINES \\
\hline 5 & CZECH REPUBLC & TRAVEL SERVIS \\
\hline 6 & ESTONIA & AVIES \\
\hline 7 & ESTONIA & ELK-AIRWAYS \\
\hline 8 & ESTONIA & ESTONIAN AIR \\
\hline 9 & FINLAND & FINNAIR \\
\hline 10 & FRANCE & AIR FRANCE \\
\hline 11 & FRANCE & CORSE-MEDITERRANEE \\
\hline 12 & FRANCE & REGIONAL \\
\hline 13 & GEORGIA & GEORGIAN AIRWAYS \\
\hline 14 & GERMANY & DEUTSCHE LUFTHANSA \\
\hline 15 & GREECE & OLYMPIC AIRWAYS \\
\hline 16 & ICELAND & ICELANDAIR \\
\hline 17 & IRELAND & RYANAIR \\
\hline 18 & ITALY & LAUDA AIR ITALY \\
\hline 19 & ITALY & NEOS SPA \\
\hline 20 & LATVIA & AIR BALTIC \\
\hline 21 & LITHUANIA & AIR LIETUVA \\
\hline 22 & LITHUANIA & TRANSAVIABALTIKA \\
\hline 23 & NETHERLANDS & KLM ROYAL DUTCH \\
\hline 24 & POLAND & LOT (POLSKIE LINIE LOTNICZE ) \\
\hline 25 & PORTUGAL & EUROATLANTIC AIRWAYS \\
\hline 26 & PORTUGAL & PORTUGALIA \\
\hline 27 & PORTUGAL & SATA AIR ACORES \\
\hline 28 & PORTUGAL & SATA INTERNACIONAL \\
\hline 29 & PORTUGAL & TAP AIR PORTUGAL \\
\hline 30 & PORTUGAL & WHITE AIRWAYS \\
\hline 31 & ROMANIA & BLUE AIR-TRANSPORT AERIAN \\
\hline 32 & ROMANIA & CARPATAIR \\
\hline
\end{tabular}


Table 3 - continued from previous page

\begin{tabular}{|c|c|c|}
\hline ID & Country & Company \\
\hline 33 & ROMANIA & MIA AIRLINES \\
\hline 34 & ROMANIA & ROMAVIA \\
\hline 35 & ROMANIA & TAROM (ROMANIAN AIR TRANSPORT) \\
\hline 36 & SPAIN & AIR EUROPA \\
\hline 37 & SPAIN & AIR NOSTRUM (IBERIA REGIONAL) \\
\hline 38 & SPAIN & BINTER CANARIAS \\
\hline 39 & SPAIN & IBERIA \\
\hline 40 & SPAIN & IBERWORLD AIRLINES \\
\hline 41 & SPAIN & SPANAIR \\
\hline 42 & SWITZERLAND & SWISS (SWISS INTERNATIONAL AIR LINES) \\
\hline 43 & SWITZERLAND & DARWIN AIRLINE \\
\hline 44 & SWITZERLAND & EDELWEISS AIR \\
\hline 45 & SWITZERLAND & FARNAIR SWITZERLAND \\
\hline 46 & SWITZERLAND & FLYBABOO \\
\hline 47 & SWITZERLAND & HELLO \\
\hline 48 & SWITZERLAND & HELVETIC AIRWAYS \\
\hline 49 & SWITZERLAND & TAG AVIATION \\
\hline 50 & SWITZERLAND & BELAIR AIRLINES \\
\hline 51 & UKRAINE & AEROSVIT AIRLINES \\
\hline 52 & UKRAINE & DNIEPROAVIA \\
\hline 53 & UKRAINE & DONBASSAERO \\
\hline 54 & UKRAINE & MOTOR SICH \\
\hline 55 & UKRAINE & ODESSA AIRLINES \\
\hline 56 & UKRAINE & WIND ROSE AVIATION COMPANY \\
\hline 57 & UKRAINE & UKRAINE INTERNATIONAL AIRLINES \\
\hline 58 & UNITED KINGDOM & FIRST CHOICE AIRWAYS \\
\hline 59 & UNITED KINGDOM & AIR CORDIAL \\
\hline 60 & UNITED KINGDOM & MYTRAVEL AIRWAYS \\
\hline 61 & UNITED KINGDOM & ASTRAEUS \\
\hline 62 & UNITED KINGDOM & BA CITYFLYER EXPRESS \\
\hline 63 & UNITED KINGDOM & THOMSONFLY LTD \\
\hline 64 & UNITED KINGDOM & BRITISH AIRWAYS \\
\hline 65 & UNITED KINGDOM & BRITISH MEDITERRANEAN AIRWAYS \\
\hline
\end{tabular}


Table 3 - continued from previous page

\begin{tabular}{|c|c|l|}
\hline ID & \multicolumn{1}{|c|}{ Country } & \multicolumn{1}{|c|}{ Company } \\
\hline 66 & UNITED KINGDOM & BRITISH MIDLAND AIRWAYS \\
67 & UNITED KINGDOM & BRITISH REGIONAL AIRLINES \\
68 & UNITED KINGDOM & JET2.COM \\
69 & UNITED KINGDOM & CITYFLYER EXPRESS \\
70 & UNITED KINGDOM & FLYGLOBESPAN.COM \\
71 & UNITED KINGDOM & EASYJET AIRLINES \\
72 & UNITED KINGDOM & EUROPEAN AVIATION AIR CHARTER \\
73 & UNITED KINGDOM & FLIGHTLINE \\
74 & UNITED KINGDOM & FLYBE.BRITISH EUROPEAN \\
75 & UNITED KINGDOM & THOMAS COOK AIRLINES (UK) LTD \\
76 & UNITED KINGDOM & GB AIRWAYS \\
77 & UNITED KINGDOM & GO FLY LIMITED \\
78 & UNITED KINGDOM & MONARCH AIRLINES \\
79 & UNITED KINGDOM & TITAN AIRWAYS \\
80 & UNITED KINGDOM & VIRGIN ATLANTIC \\
\hline
\end{tabular}


Table 4: Efficiency scores in the network model, all airlines

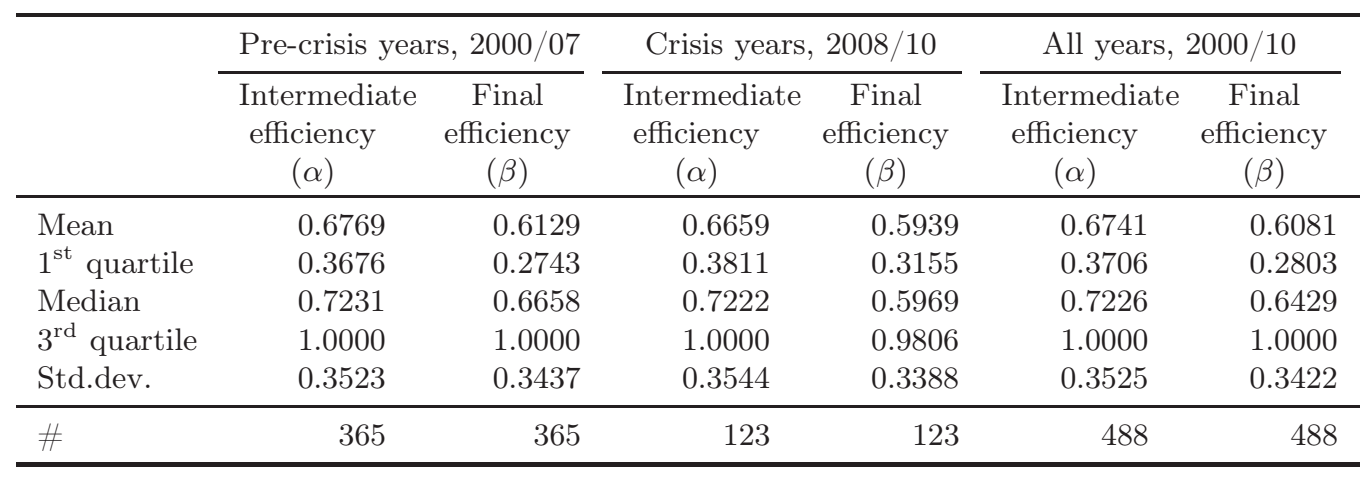


Table 5: Efficiency scores in the network model, low-cost vs. full-service airlines

\begin{tabular}{|c|c|c|c|c|c|c|c|}
\hline & & \multicolumn{2}{|c|}{ Pre-crisis years, 2000/07 } & \multicolumn{2}{|c|}{ Crisis years, 2008/10 } & \multicolumn{2}{|c|}{ All years, 2000/10 } \\
\hline & & $\begin{array}{l}\text { Intermediate } \\
\text { efficiency } \\
(\alpha)\end{array}$ & $\begin{array}{c}\text { Final } \\
\text { efficiency } \\
(\beta)\end{array}$ & $\begin{array}{l}\text { Intermediate } \\
\text { efficiency } \\
(\alpha)\end{array}$ & $\begin{array}{c}\text { Final } \\
\text { efficiency } \\
(\beta) \\
\end{array}$ & $\begin{array}{l}\text { Intermediate } \\
\text { efficiency } \\
(\alpha)\end{array}$ & $\begin{array}{c}\text { Final } \\
\text { efficiency } \\
(\beta) \\
\end{array}$ \\
\hline \multirow{6}{*}{ Low-cost airlines } & Mean & 0.6901 & 0.6570 & 0.7747 & 0.7494 & 0.7113 & 0.6801 \\
\hline & $1^{\text {st }}$ quartile & 0.5226 & 0.4183 & 0.6362 & 0.5955 & 0.5399 & 0.4683 \\
\hline & Median & 0.7500 & 0.7375 & 0.7801 & 0.8370 & 0.7528 & 0.7489 \\
\hline & $3^{\text {rd }}$ quartile & 0.8994 & 0.8999 & 0.9905 & 0.9903 & 0.9159 & 0.9397 \\
\hline & Std.dev. & 0.2755 & 0.3005 & 0.1998 & 0.2446 & 0.2600 & 0.2887 \\
\hline & $\#$ & 54 & 54 & 18 & 18 & 72 & 72 \\
\hline \multirow{6}{*}{ Full-service airlines } & Mean & 0.6746 & 0.6052 & 0.6473 & 0.5673 & 0.6677 & 0.5956 \\
\hline & $1^{\text {st }}$ quartile & 0.3485 & 0.2666 & 0.3426 & 0.2684 & 0.3471 & 0.2670 \\
\hline & Median & 0.7150 & 0.6512 & 0.6864 & 0.5666 & 0.7136 & 0.6298 \\
\hline & $3^{\text {rd }}$ quartile & 1.0000 & 1.0000 & 1.0000 & 0.9597 & 1.0000 & 1.0000 \\
\hline & Std.dev. & 0.3643 & 0.3506 & 0.3721 & 0.3463 & 0.3660 & 0.3495 \\
\hline & $\#$ & 311 & 311 & 105 & 105 & 416 & 416 \\
\hline
\end{tabular}


Table 6: Efficiency scores in the network model, EU15 ${ }^{\mathrm{a}}$ vs. non-EU15 airlines

\begin{tabular}{|c|c|c|c|c|c|c|c|}
\hline & & \multicolumn{2}{|c|}{ Pre-crisis years, $2000 / 07$} & \multicolumn{2}{|c|}{ Crisis years, $2008 / 10$} & \multicolumn{2}{|c|}{ All years, $2000 / 10$} \\
\hline & & $\begin{array}{l}\text { Intermediate } \\
\text { efficiency } \\
(\alpha)\end{array}$ & $\begin{array}{c}\text { Final } \\
\text { efficiency } \\
(\beta)\end{array}$ & $\begin{array}{l}\text { Intermediate } \\
\text { efficiency } \\
(\alpha)\end{array}$ & $\begin{array}{c}\text { Final } \\
\text { efficiency } \\
(\beta)\end{array}$ & $\begin{array}{l}\text { Intermediate } \\
\text { efficiency } \\
(\alpha)\end{array}$ & $\begin{array}{c}\text { Final } \\
\text { efficiency } \\
(\beta)\end{array}$ \\
\hline \multirow{6}{*}{ EU15 airlines } & Mean & 0.7448 & 0.6890 & 0.7183 & 0.6620 & 0.7386 & 0.6827 \\
\hline & $1^{\text {st }}$ quartile & 0.4992 & 0.3829 & 0.5035 & 0.4156 & 0.5020 & 0.3855 \\
\hline & Median & 0.8374 & 0.7873 & 0.8230 & 0.7180 & 0.8331 & 0.7767 \\
\hline & $3^{\text {rd }}$ quartile & 1.0000 & 1.0000 & 1.0000 & 1.0000 & 1.0000 & 1.0000 \\
\hline & Std.dev. & 0.3093 & 0.3156 & 0.3267 & 0.3328 & 0.3132 & 0.3195 \\
\hline & $\#$ & 286 & 286 & 87 & 87 & 373 & 373 \\
\hline \multirow{6}{*}{ Non-EU15 airlines } & Mean & 0.4311 & 0.3375 & 0.5393 & 0.4295 & 0.4650 & 0.3663 \\
\hline & $1^{\text {st }}$ quartile & 0.1544 & 0.0922 & 0.2784 & 0.1724 & 0.1636 & 0.1109 \\
\hline & Median & 0.3345 & 0.2478 & 0.4207 & 0.3734 & 0.3651 & 0.3083 \\
\hline & $3^{\text {rd }}$ quartile & 0.5263 & 0.5068 & 0.9072 & 0.6425 & 0.6918 & 0.5912 \\
\hline & Std.dev. & 0.3893 & 0.2989 & 0.3904 & 0.2975 & 0.3912 & 0.3002 \\
\hline & $\#$ & 79 & 79 & 36 & 36 & 115 & 115 \\
\hline
\end{tabular}

${ }^{a}$ Airlines from EU15 countries plus Iceland and Switzerland. 
Figure 1: A black box model for the airline industry

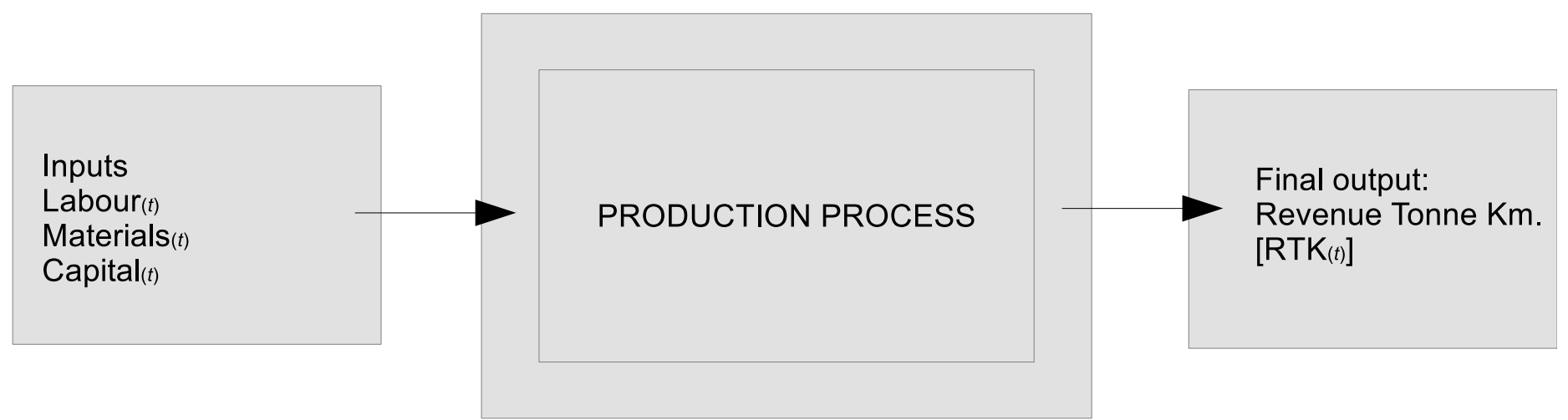


Figure 2: A chained model for the airline industry

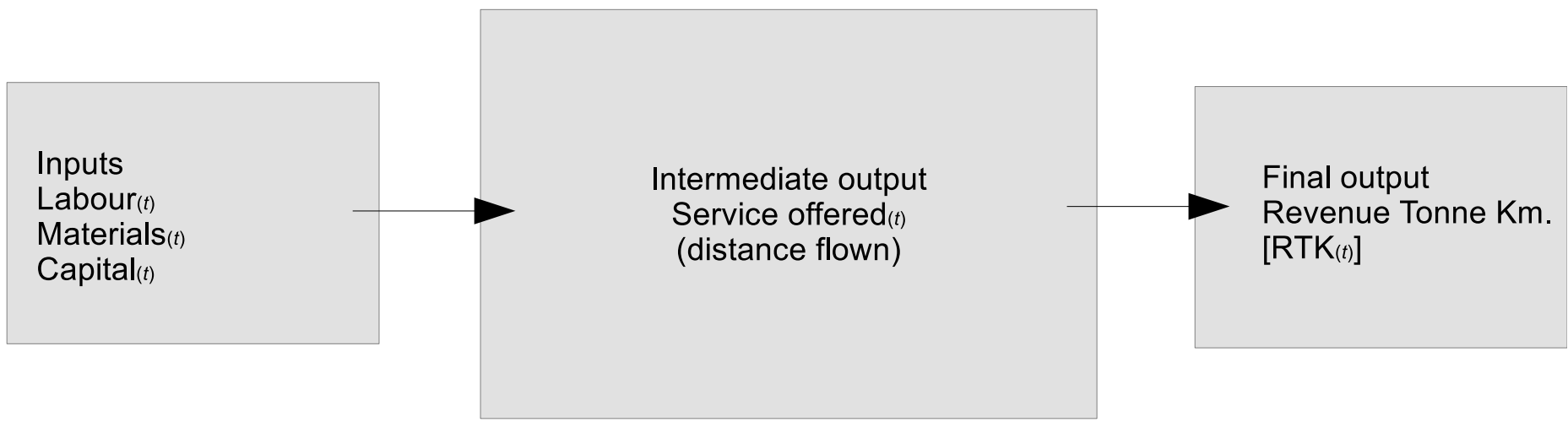


Figure 3: A network model for the airline industry

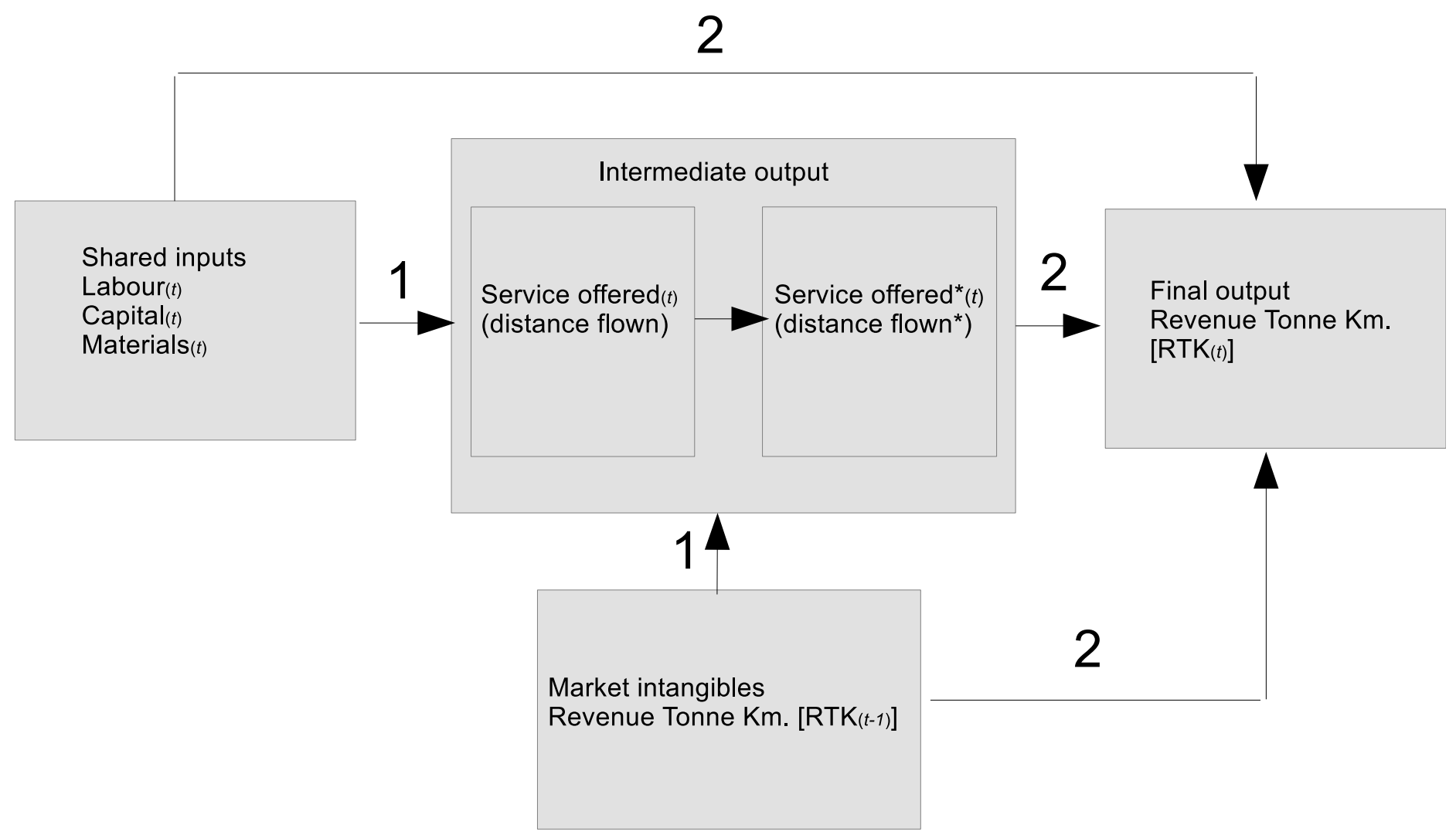


Figure 4: Kernel density plots, efficiency scores (final)

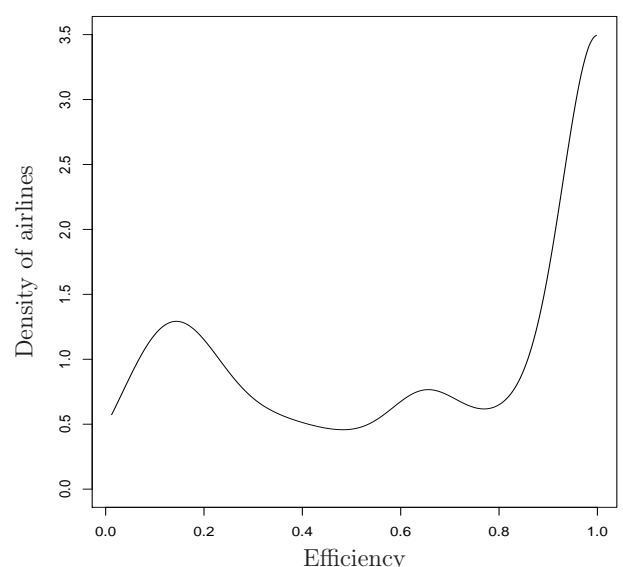

(a) $2000 / 03$

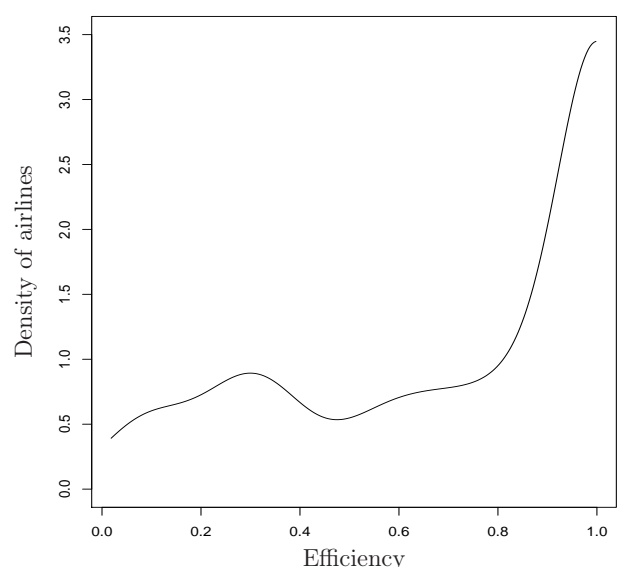

(b) $2004 / 07$

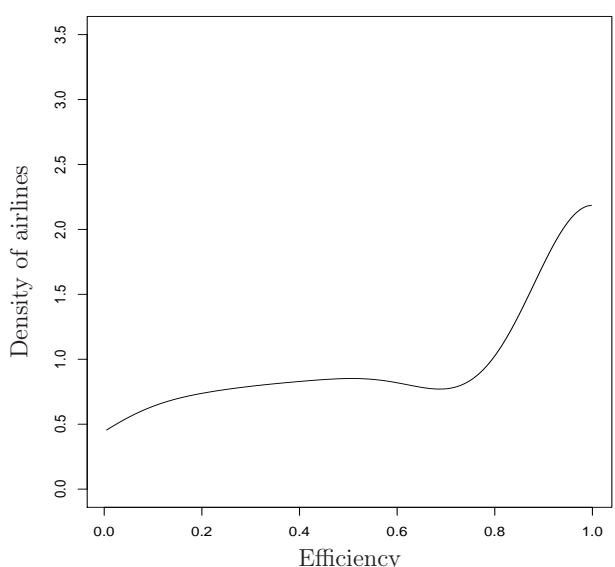

(c) $2008 / 10$

Notes: All figures contain densities estimated using kernel density estimation for the final efficiency scores. The reflection method (Silverman, 1986) was used in order to "reflect" or "mirror" the probability mass above 1 which should not exist since efficiencies lie in the ]0,1] interval. A Gaussian kernel was chosen, and bandwidths were estimated using plug-in methods (Sheather and Jones, 1991). 
Figure 5: Kernel density plots, efficiency scores (intermediate)

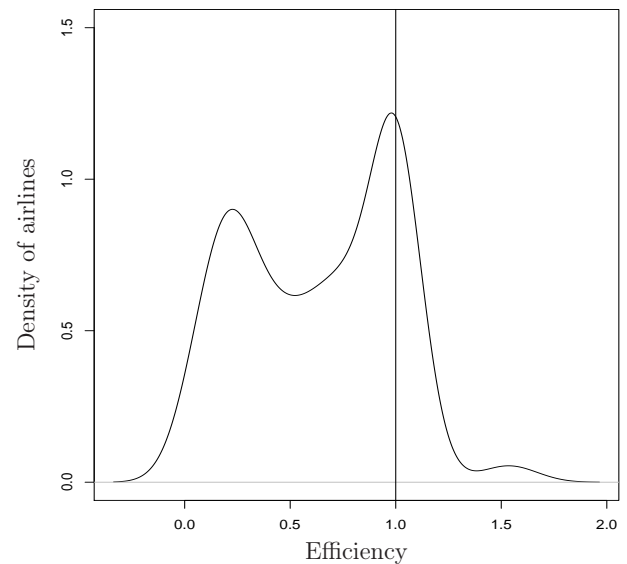

(a) $2000 / 03$

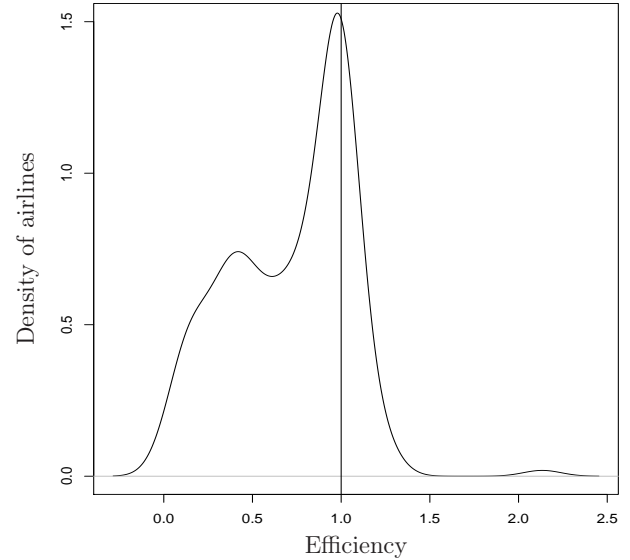

(b) $2004 / 07$

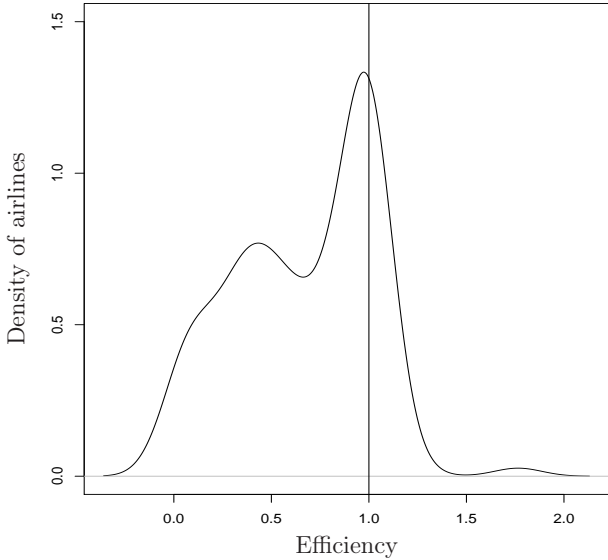

(c) $2008 / 10$

Notes: All figures contain densities estimated using kernel density estimation for the final efficiency scores. A Gaussian kernel was chosen, and bandwidths were estimated using plug-in methods (Sheather and Jones, 1991). 
Figure 6: Kernel density plots, efficiency scores, low-cost vs. full-service airlines

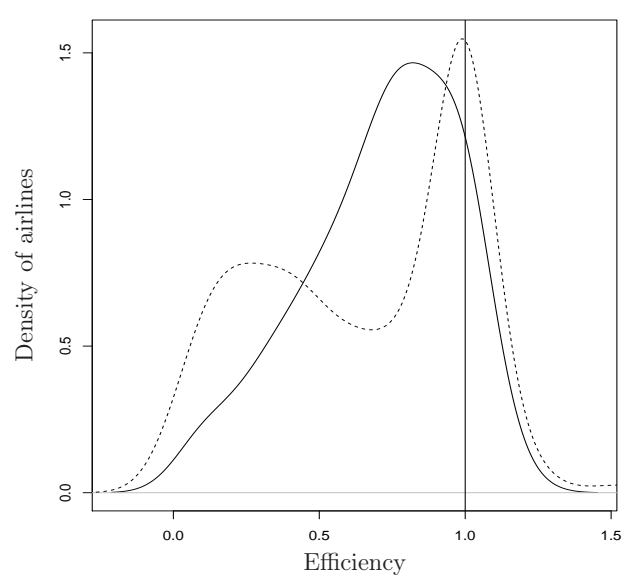

(a) Intermediate

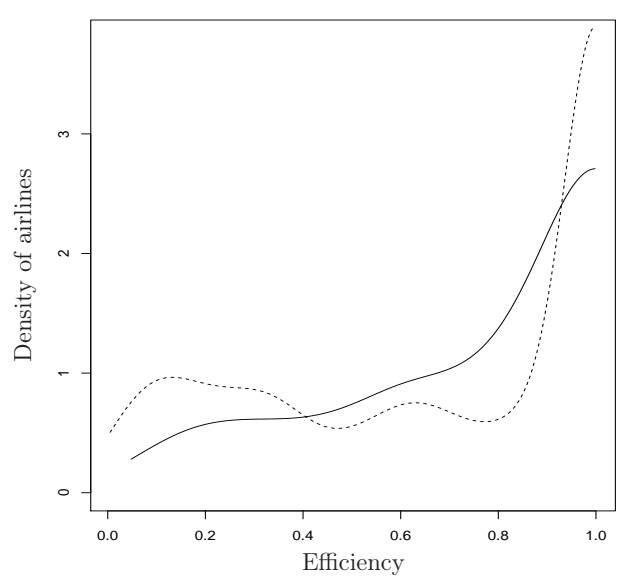

(b) Final

EU15

Non-EU15

Notes: All figures contain densities estimated using kernel density estimation for efficiency scores. In the case of final efficiency scores, the reflection method (Silverman, 1986) was used in order to "reflect" or "mirror" the probability mass above 1 which should not exist since efficiencies lie in the $] 0,1]$ interval. A Gaussian kernel was chosen, and bandwidths were estimated using plug-in methods (Sheather and Jones, 1991). 
Figure 7: Kernel density plots, efficiency scores, EU15 vs. non-EU15 airlines

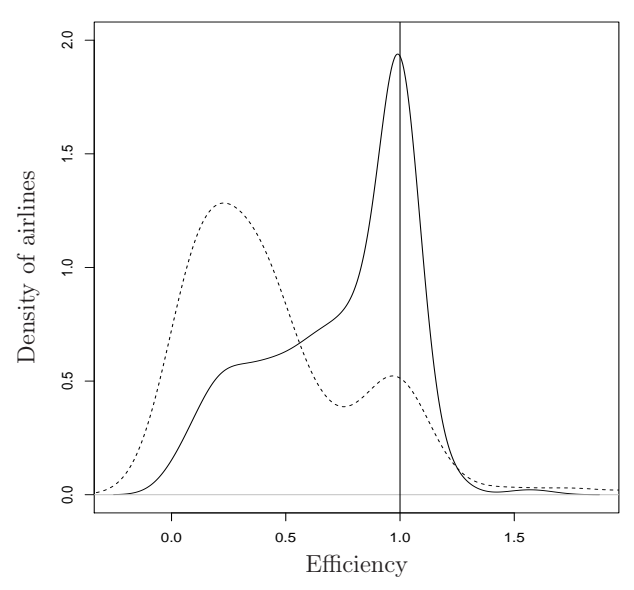

(a) Intermediate

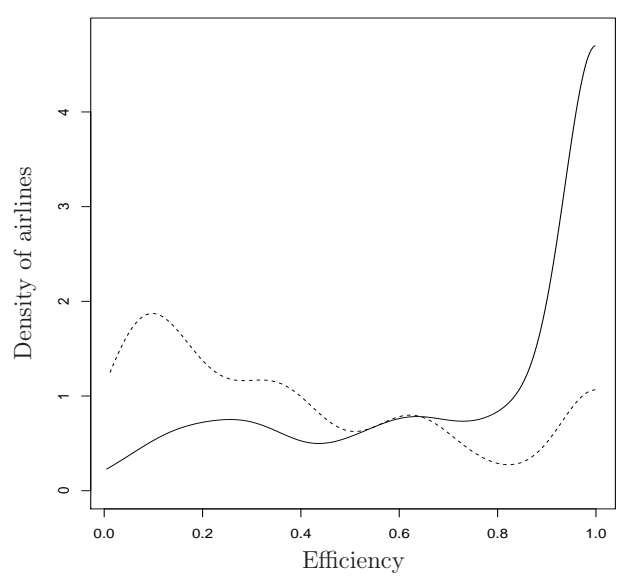

(b) Final

EU15 Non-EU15 ….....

Notes: All figures contain densities estimated using kernel density estimation for efficiency scores. In the case of final efficiency scores, the reflection method (Silverman, 1986) was used in order to "reflect" or "mirror" the probability mass above 1 which should not exist since efficiencies lie in the $] 0,1]$ interval. A Gaussian kernel was chosen, and bandwidths were estimated using plug-in methods (Sheather and Jones, 1991). 